\title{
Spatial and temporal patterns of dispersion in meiobenthic copepods
}

\author{
Bin Sun, John W. Fleeger \\ Department of Zoology, Louisiana State University, Baton Rouge, Louisiana 70803, USA
}

\begin{abstract}
Small-scale spatial pattern (dispersion) of meiobenthic harpacticoid copepods was surveyed in 2 tidal habitats, a shallow pond and a mudflat, in Louisiana, USA. Replicate sampling arrays $(5 \times 5$ or $5 \times 8)$ of contiguous corers $(8 \mathrm{~mm}$ ID) were employed seasonally to determine the temporal variation in aggregation tendencies. In order to further detect the scale of variability, 3 spatial scales (dekameters, meters and centimeters) were sampled at the pond site. Patch size and aggregation tendencies were inferred by spatial autocorrelation from correlograms using Moran's $I$ value plotted against distance. Two-way ANOVA measured variations at the 3 different spatial scales. For all abundant harpacticoids, significant small-scale aggregations were remarkably consistent across different collecting dates and habitats although patch size was somewhat variable. Two spatial patterns were common among the 66 species and replicate combinations. One, which occurred most often, consisted of several small patches (1 to $4 \mathrm{~cm}^{2}$ ) irregularly arranged throughout the sampling area. The less frequent pattern consisted of fewer, larger patches $\left(6\right.$ to $\left.20 \mathrm{~cm}^{2}\right)$. Patchiness could be detected even though variance-to-mean ratios $\left(s^{2} / \bar{x}\right)$ did not always indicate significant aggregation, and aggregation tendencies and patch size were not clearly related to density. Among the 3 spatial scales, small-scale variation (cm scale) contributed most to the components of variance (57 to $76 \%$ ). Variation among replicate core sets was high suggesting that contiguous core sampling should always be replicated. Our results also suggest that aggregation tendencies are a function of very small-scale processes that may be related to sediment microtopographic features or behavior
\end{abstract}

\section{INTRODUCTION}

The small size of meiofauna $(<1 \mathrm{~mm}$ body length) precludes investigations that require the observation and manipulation of individuals in sediments. Nevertheless, small size is an advantage in benthic research in that manageable samples with many individuals can be easily obtained to provide detailed information on spatial distribution. Spatial pattern is therefore frequently used to elucidate the relationships between meiofauna and their environment. Organism-habitat interactions, e.g. the relationship between sediment topography and spatial distribution (Hogue \& Miller 1981), physical structure effects (Palmer 1986, Thistle \& Eckman 1988), and sediment disturbance (Hogue 1982), as well as interorganism relationships such as with food resources (Decho \& Fleeger 1988), and the importance of sizestructure (Kern \& Bell 1984) have been examined successfully by observing spatial patterns in meiofaunal abundance. Additionally, an understanding of spatial distribution is necessary to obtain reliable population estimates and to minimize sample size and processing time for meiofauna (Fleeger et al. 1988).
Meiofauna have been shown to be aggregated at a variety of spatial scales. Small-scale patchiness $(\mathrm{cm}$ scale) is routinely detected but meso-scale variability ( $m$ scale) has also been noted. Small-scale patchiness has been found in such a wide variety of habitats, e.g. intertidal mud and sand (Nixon 1976, Findlay 1981, 1982, Hogue \& Miller 1981, Hicks 1984), subtidal (Hogue 1982), marsh (Decho \& Fleeger 1988, Fleeger et al. 1990) and deep-sea (Eckman \& Thistle 1988), that it is almost universally accepted for meiofauna (Fleeger $\&$ Decho 1987). Meso-scale variability has been studied much less frequently (Phillips \& Fleeger 1985), but can also be a source of sampling error. Kern \& Bell (1984) suggest that sampling effort routinely be widened to include several $\mathrm{m}^{2}$ surface area to reduce this source of variation.

Unfortunately, most measurements of patchiness are done only once or twice in a relatively small area (less than $1 \mathrm{~m}^{2}$ ), and it is not clear whether the scale of patchiness remains constant over time and space. Understanding how dispersion changes through time and space may provide very useful information in establishing the relationship between environmental 
factors and meiofaunal distribution. For example, if the scale of patchiness does not vary over seasons, factors that are responsible may be those that act continually (e.g. behavior or sediment topography), rather than those factors that have a strong seasonal variation (such as temperature or salinity). By using contiguous cores and autocorrelation analysis, Fleeger et al. (1990) found that the aggregation intensity of harpacticoid copepods did not change through a tidal cycle although the densities of some species significantly differed. However, it is still unclear if the small-scale distribution of meiofauna remains constant through much longer times (e.g. seasonally) or throughout larger (mesoscale) areas.

The purpose of this study was to address the following questions: (1) Are small-scale aggregations of harpacticoid copepods consistent among sampling dates and sites throughout a locale? (2) Is the scale of variability a function of small-scale or meso-scale patchiness? (3) What is the patch size of aggregations? (4) Is aggregation intensity a function of population density?

\section{METHODS AND MATERIALS}

Site. The study area, located in Terrebonne Parish, near Cocodrie, Louisiana, USA $\left(29^{\circ} 15^{\prime} \mathrm{N} ; 91^{\circ} 21^{\prime} \mathrm{W}\right)$, is characterized as a salt marsh dominated by the cordgrass Spartina alterniflora. The 2 study sites, a small pond (SP) and a mudflat (MF), have been well described physically and biologically with a considerable ecological baseline on the meiofaunal assemblage (Chandler \& Fleeger 1983, Phillips \& Fleeger 1985, Decho \& Fleeger 1988). Water movement is largely wind-dominated with small diurnal tidal amplitudes $(0.3 \mathrm{~m})$ and wide salinity fluctuations ( 2 to $26 \mathrm{ppt}$ ).

The 2 sampling sites represent different habitats. The SP site $(25 \times 15 \mathrm{~m})$ is a protected, shallow enclosure (0.5 $\mathrm{m}$ in depth) with a narrow channel visible along one side of the pond at low tide. The site has no large structures (macrofauna tubes or grass clumps) that protrude from the bed, but small-scale (cm) irregularities are prevalent. Sediments are largely silt-clay with no apparent large-scale gradients. The mudflat site $(20 \times 4 \mathrm{~m})$ is an intertidal area between the Spartina alterniflora marsh and a frequently travelled bayou and is commonly exposed to disturbances such as boat waves. Sediments are muddy but slightly sandier than the pond.

Sampling. Two sampling strategies were used in this study. First, small contiguous core samples were taken to determine the patch size and spatial and temporal variation in aggregation intensity. Secondly, samples from 3 different spatial scales (dekameter, meter and centimeter) of randomly chosen locations in the SP site were collected to determine the spatial scale of distribution using analysis of variance techniques

For contiguous core sampling, harpacticoid copepods were collected on 4 dates, 21 January 1989, 18 March 1989, 15 July 1989 and 13 January 1990, when sediment was air exposed at both sites. At each site, 3 replicate sampling arrays were taken over a small distance (less than 1 to $2 \mathrm{~m}^{2}$ ) during each collection. The sampling units were constructed from $2.5 \mathrm{ml}$ syringes ( $8 \mathrm{~mm}$ in inner diameter) with both ends cut off, and were glued together to form a single array (Fleeger et al. 1990). The distance between the centers of 2 adjoining corers in the contiguous grid was $10.5 \mathrm{~mm}$. On the first 2 sampling dates, the sampling array consisted of 25 corers $(5 \times 5)$ with a total surface area of $28 \mathrm{~cm}^{2}$. For the last 2 collections, 15 corers were added to increase the size of the original sampling unit to a $5 \times 8$ array $(45$ $\mathrm{cm}^{2}$ ). Sampling units were always carefully pushed into the sediment to a depth of at least $2 \mathrm{~cm}$. After removal from the sediment, each sampling unit was immediately pushed into thinly rolled modelling clay to hold sediment into the corers before returning to the Louisiana University Marine Consortium's (LUMCON) laboratory (about $1 \mathrm{~km}$ from the sampling sites). Cores were numbered by row and column to denote spatial coordinates, and sediment was extruded into an individually labelled vial, fixed with $5 \%$ formaldehyde and stained with Rose Bengal.

For the spatial variation study, harpacticoid copepods were collected on 2 occasions on 18 March 1989 at the SP site. Three sampling scales (dekameters, meters and centimeters) were assigned in the pond (Fig. 1). At the dekameter scale, three $5 \mathrm{~m}$ long transects were positioned randomly and parallel to the small creek. Transects were fixed and sampled on both occasions. The distance between the ends of Transects $A$

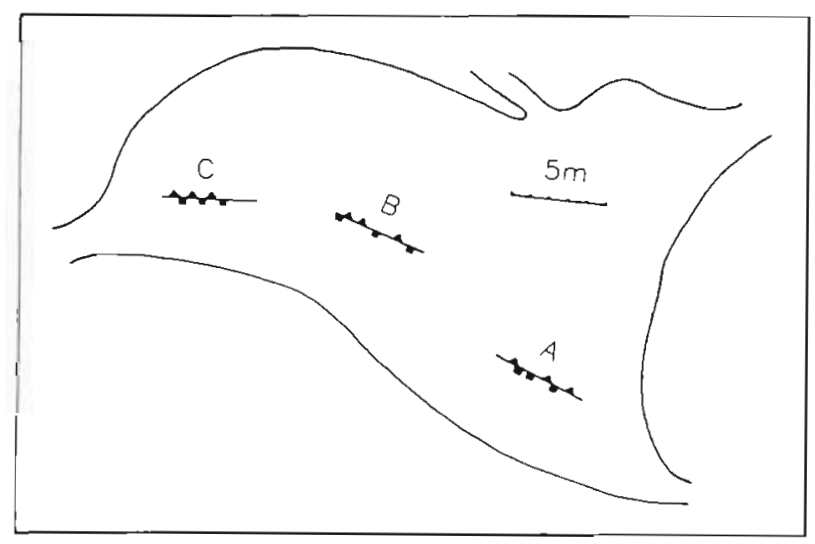

Fig. 1. Positions of 3 transects and sampling units for the scale of variability sampling in the small pond (SP) site. (-) First sampling time; $(\mathbf{\Lambda})$ second sampling time 
and $\mathrm{B}$ was $7 \mathrm{~m}$ and between $\mathrm{B}$ and $\mathrm{C}, 5 \mathrm{~m}$. Along each transect, at the meter scale, 3 sample units locations $(10 \times 10 \mathrm{~cm}$ in size) were randomly assigned at each sampling time. Within each sample location, at the centimeter scale, 5 cores were taken by modified syringes (26.5 $\mathrm{mm}$ diameter) with the same distance (ca $3 \mathrm{~cm}$ ) between neighboring cores. Water (about $10 \mathrm{~cm}$ in depth) covered the sampling area during both collecting times. The upper $2 \mathrm{~cm}$ of sediment of each core was removed to an individually labeled jar and treated with formaldehyde and Rose Bengal.

In the laboratory, all the samples were treated by sonication and sieving. Samples from the spatial-variability collections were extracted using density gradient centrifugation with Ludox (Fleeger \& Chandler 1983). Harpacticoid copepods retained on a $63 \mu \mathrm{m}$ sieve were enumerated and identified to species.

Data analysis. Autocorrelation analyses were conducted to detect distributional pattern and patch size of harpacticoid copepods based on Moran's spatial autocorrelation coefficient $I$ (Sokal 1979, Cliff et al. 1975). This technique has been applied frequently to biological systems including the marine benthos (Thistle 1978, Hogue \& Miller 1981, Jumars \& Eckman 1983, Decho \& Fleeger 1988, Fleeger et al. 1990). Spatial autocorrelation exists if the observed value of the variable at one locality is dependent on the value at neighboring localities (Sokal \& Oden 1978). In other words, positive autocorrelation means that high values of the variable at one locality are associated with high values in neighboring localities. If high and low values alternate, autocorrelation is negative. Spatial correlograms describe the relationship between spatial autocorrelation coefficients and geographic distance, and patch size corresponds to the distance at which the correlogram first turns zero or negative (Sokal 1983, Sokal \& Thomson 1987). In this study, the first distance class contained only adjacent cores and the second distance class included only cores in a diagonal position. The subsequent classes were more arbitrary but provided a uniform sample size in each class. The distance assigned to each distance class was the class mean distance. I values were transformed to $Z$ variates (standard normal variates) in order to more easily judge significance levels. Variance-to-mean ratio $\left(s^{2} / \bar{x}\right)$ was also calculated on each replicate as an index of dispersion to compare to the autocorrelation results (Elliott 1977).

A 3-way ANOVA was employed to test the effects of collection date, transect and species in the spatial variability analysis. For each dominant species, a 2-way ANOVA was used to estimate differences between levels and the variance contribution of the 3 spatial scales. All data for ANOVA were transformed by $\log _{e}(x+1)$

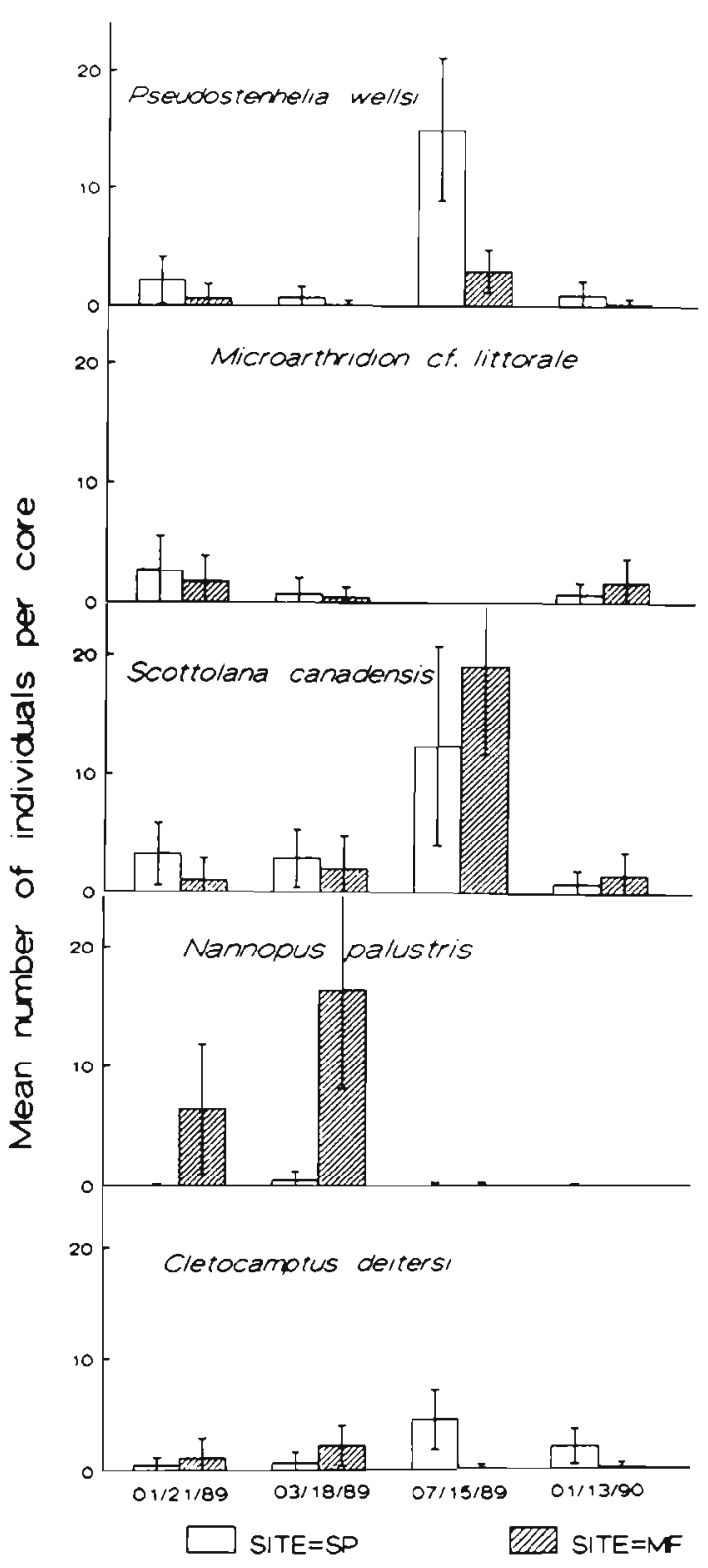

Fig. 2. Seasonal changes of abundance for 5 dominant species at 2 collecting sites. SP: small pond; MF: mudflat

\section{RESULTS}

\section{Small-scale pattern}

Harpacticoid copepod species were designated 'abundant' if more than 18 or 25 individuals appeared in a replicate sampling array on the first 2 or last 2 collecting dates respectively. Five species were found to be abundant and were included in further data calculations from contiguous cores. Other harpacticoids were judged to be too rare to warrant statistical analysis. Abundance patterns for these 5 species demon- 
strated remarkable temporal changes among sample collections (Fig. 2). Scottolana canadensis (Willey) was the most abundant among the 5 species with peak values appearing in summer. Pseudostenhelia wellsi Coull \& Fleeger was also very abundant in the summer but more abundant at the SP site than the MF site. Nannopus palustris was only abundant in the spring at the MF site. Although Microarthridion cf. littorale and Cletocamptus deitersi (Richard) did not have extreme peak densities, both species displayed large changes in abundance between collections.

Autocorrelation correlograms illustrate a consistent pattern of nori-random distributions for all 5 abundant species (Tables $1 \& 2$ ). Of 66 species and replicate combinations only one (Scottolana canadensis, March $18, \mathrm{SP}$, replicate 2) showed no significant positive or negative autocorrelation at any distance. Sixty-four $(97 \%$ of total) species and replicate combinations had

Table 1. Spatial autocorrelation (Moran's autocorrelation coefficient $I_{\mathrm{t}}$ sampling array $5 \times 5$ ) and variance to mean ratio $\left(s_{2} / \bar{x}\right)$ for the 5 dominant species on January 2 (A) and March 18 (B), +: significant positive correlation; - : significant negative correlation. Rep.: replicate no.

\begin{tabular}{|c|c|c|c|c|c|c|c|c|c|c|c|c|}
\hline \multirow[t]{2}{*}{ Date } & \multirow[t]{2}{*}{ Site } & \multirow[t]{2}{*}{ Rep. } & \multirow[t]{2}{*}{$s^{2} / \bar{x}$} & \multicolumn{9}{|c|}{ Mid-point } \\
\hline & & & & 1.0 & 1.4 & 2.0 & 2.2 & 2.9 & 3.2 & 3.7 & 4.2 & 5.1 \\
\hline \multicolumn{13}{|c|}{ Pseudosienhelia weilsi } \\
\hline \multirow[t]{4}{*}{ A } & SP & 1 & $1.66^{\circ}$ & $+^{\bullet}$ & & & & & $+{ }^{*}$ & & & \\
\hline & & 2 & $1.77^{\circ}$ & $+\cdots$ & & & & & & & & $-\cdots$ \\
\hline & & 3 & $1.57^{\circ}$ & $+^{\cdot}$ & & & & & & & & \\
\hline & $M F$ & 1 & 1.24 & $+^{\cdot}$ & & & & & $+^{\circ}$ & & & \\
\hline \multirow[t]{2}{*}{ B } & SP & 2 & $1.77^{\cdots}$ & $+\cdots$ & & & & & & & & $-\cdots$ \\
\hline & & 3 & 0.94 & $+\cdots$ & & $-\cdot$ & & & & & & \\
\hline \multicolumn{13}{|c|}{ Microarthridion cf. littorale } \\
\hline \multirow[t]{5}{*}{ A } & $\mathrm{SP}$ & 1 & $2.30^{\cdots}$ & $+\cdots$ & & & & & & & & $-\cdot$ \\
\hline & & 2 & 1.13 & $t^{\cdot}$ & & & $+{ }^{*}$ & & & & & \\
\hline & & 3 & $2.03^{\cdots}$ & $+\cdots$ & & & & & & $-\cdots$ & & \\
\hline & $\mathrm{MF}$ & 1 & 1.30 & $+\cdots$ & & & & & & & & \\
\hline & & 2 & 0.91 & $+\cdots$ & & & & & & & & \\
\hline \multirow[t]{2}{*}{ B } & $\mathrm{SP}$ & 3 & $3.14^{\cdots}$ & $+\cdots$ & & & & & & & & \\
\hline & MF & 3 & 1.14 & $+{ }^{*}$ & & & & & $-\cdot$ & & & \\
\hline \multicolumn{13}{|c|}{ Scottolana canadensis } \\
\hline \multirow[t]{4}{*}{ A } & $\mathrm{SP}$ & 1 & $2.26^{\circ}$ & $+\cdots$ & & & & & & & & \\
\hline & & 2 & 1.21 & $+\cdot$ & & & & & & & & \\
\hline & & 3 & $1.74^{\circ}$ & $+\cdots$ & & & & & & & & \\
\hline & $\mathrm{MF}$ & 1 & $1.60^{\circ}$ & $+\cdots$ & & $+^{\cdot}$ & & & & $-\cdot$ & & \\
\hline \multirow[t]{5}{*}{$\mathrm{B}$} & SP & 1 & $1.52^{\circ}$ & $+\cdot$ & & & & & $+\cdots$ & & & \\
\hline & & 2 & $1.99^{\circ} \cdot$ & $+\cdots$ & & & & & & & $++^{\cdot}$ & \\
\hline & & 3 & $2.28^{\circ}$ & $+\cdots$ & & & & & & & $-\cdot$ & \\
\hline & & 2 & 1.14 & & & & & & & & & \\
\hline & & 3 & $3.37^{\cdots}$ & $+\cdots$ & & & & $+{ }^{*}$ & & & $-\cdot$ & $-\cdots$ \\
\hline \multicolumn{13}{|c|}{ Nannopus palustris } \\
\hline \multirow[t]{3}{*}{ A } & $\mathrm{MF}$ & 1 & 1.50 & $+\cdots$ & & & & & & & & \\
\hline & & 2 & $3.46^{\cdots}$ & $+\cdots$ & & & & $+\cdot$ & & & & \\
\hline & & 3 & $2.58^{\circ} \cdot$ & $+\cdots$ & & & & & & & & \\
\hline \multirow[t]{3}{*}{ B } & $\mathrm{MF}$ & 1 & $2.90^{*}$ & $+\cdots$ & & & $-\cdot$ & & & & $++^{\cdot}$ & \\
\hline & & 2 & $3.08^{\circ}$ & $++^{\bullet}$ & & & & & & & & \\
\hline & & 3 & $4.58^{\circ}$ & $+{ }^{\cdot}$ & $+\cdots$ & & & & & & & \\
\hline \multicolumn{13}{|c|}{ Cletocamptus deitersi } \\
\hline \multirow[t]{3}{*}{ A } & SP & 3 & 0.77 & $+{ }^{\cdot}$ & & & & & & & & \\
\hline & MF & 1 & $1.53^{\circ}$ & & & & & $+^{\cdot}$ & & _. & & $-{ }^{\cdot}$ \\
\hline & & 2 & 1.07 & $+\cdots$ & $+\cdots$ & & $-{ }^{*}$ & & & - & & \\
\hline \multirow[t]{3}{*}{$\mathrm{B}$} & MF & 1 & 1.39 & $+\cdots$ & & & & & & & & \\
\hline & & 2 & 1.04 & $+\cdots$ & & & & & & & & \\
\hline & & 3 & 1.38 & $+\cdots$ & & & & & & & & \\
\hline $\begin{array}{l}\text { Moran's } \\
s^{2} / \bar{x}: \cdot c\end{array}$ & $\begin{array}{l}0.01< \\
p<0\end{array}$ & $\begin{array}{l}0.05 \\
\because p\end{array}$ & $\begin{array}{l}0.001< \\
.01\end{array}$ & $1 ; \cdots$ & $<0.001$ & & & & & & & \\
\hline
\end{tabular}


Table 2. Spatial autocorrelation (Moran's autocorrelation coefficient $I$, sampling array $5 \times 8$ ) and variance to mean ratio $\left(s_{2} / \bar{x}\right)$ for the 4 dominant species on July 15 (C) and Jan 13/(90) (D). +: significant positive correlation; - : significant negative correlation. Rep.: replicate no.

\begin{tabular}{|c|c|c|c|c|c|c|c|c|c|c|c|c|c|c|c|c|c|c|}
\hline \multirow[t]{2}{*}{ Date } & \multirow[t]{2}{*}{ Site } & \multirow[t]{2}{*}{ Rep. } & \multirow[t]{2}{*}{$s^{2} / \bar{x}$} & \multicolumn{15}{|c|}{ Mid-point } \\
\hline & & & & 1.0 & 1.4 & 2.0 & 2.2 & 2.9 & 3.2 & 3.7 & 4.2 & 5.0 & 5.4 & 5.9 & 6.4 & 6.9 & 7.3 & 7.8 \\
\hline \multicolumn{19}{|c|}{ Pseudostenhelia wellsi } \\
\hline \multirow[t]{6}{*}{$\mathrm{C}$} & $\mathrm{SP}$ & 1 & $2.14^{\cdots}$ & $+\cdots$ & $+^{\cdot}$ & $+^{\cdot}$ & $+\cdots$ & & & & & $-\cdots$ & $-\cdot$ & $-\cdots$ & $-{ }^{*}$ & $-\cdots$ & $-\cdots$ & \\
\hline & & 2 & $3.69^{\circ}$ & $+\cdots$ & $++^{\cdot}$ & & & & $-\cdots$ & & $-\cdots$ & & & & $-{ }^{\cdot}$ & & $+\cdots$ & $++^{\cdot}$ \\
\hline & & 3 & 1.35 & $+\cdots$ & & & & & & & & $-\cdot$ & & $-\cdot$ & & & & \\
\hline & MF & 1 & 1.44 & $+\cdots$ & & & & & & & & $-{ }^{*}$ & & & & & & \\
\hline & & 2 & 0.91 & $+\cdots$ & & & & & & & & & $+{ }^{*}$ & & & & & \\
\hline & & 3 & 0.73 & $+\cdots$ & & & & & & & & & & & & & & \\
\hline \multirow[t]{2}{*}{$\mathrm{D}$} & SP & 1 & 1.11 & $+\cdots$ & & & & & & & & & & & & & & \\
\hline & & 3 & $1.55^{\circ}$ & $+\cdots$ & & & & & & & & & & & & & & \\
\hline \multicolumn{19}{|c|}{ Microarthridion cf. littorale } \\
\hline \multirow[t]{6}{*}{$\mathrm{D}$} & $\mathrm{SP}$ & 1 & 1.15 & $+\cdots$ & & & & & & & & & $+^{\bullet}$ & & & & & $+^{\cdot}$ \\
\hline & & 2 & $1.46^{\circ}$ & $+\cdots$ & $-{ }^{\cdot}$ & & & & & & & & & & & & & \\
\hline & & 3 & 1.42 & $+\cdots$ & & & & & & & & & & & & & & \\
\hline & $\mathrm{MF}$ & 1 & 1.19 & $+\cdots$ & & & $+\cdots$ & & & & & & & & & & & \\
\hline & & 2 & 1.29 & $+\cdots$ & $+\cdots$ & & & & & & $-\cdot$ & & & & & & & \\
\hline & & 3 & $2.02^{\cdots}$ & $+\cdots$ & $+\cdot$ & & & & $-\cdots$ & $-{ }^{\cdot}$ & $-\cdots$ & & & & & & & \\
\hline \multicolumn{19}{|c|}{ Scottolana canadensis } \\
\hline \multirow[t]{6}{*}{$\mathrm{C}$} & $\mathrm{SP}$ & 1 & $3.21^{\cdots}$ & $+\cdots$ & & & & & & $-\cdot$ & & & & & & & & \\
\hline & & 2 & $2.61^{\cdots}$ & $+\cdots$ & $+^{\bullet}$ & & & & $-{ }^{\cdot}$ & & $-\cdots$ & & & & & $+^{*}$ & + & $+\cdots$ \\
\hline & & 3 & $4.58^{*}$ & $+\cdots$ & $+\cdots$ & & & & & $-\cdots$ & $-\cdots$ & $-\cdot$ & & & & & & \\
\hline & $\mathrm{MF}$ & 1 & $3.48^{*}$ & $+\cdots$ & & & & & & & & $+\cdot$ & & & & & & \\
\hline & & 2 & $2.34^{\cdots}$ & $+\cdots$ & & & & $+{ }^{*}$ & & & & & & & & & & \\
\hline & & 3 & $1.73^{\cdots}$ & $+\cdots$ & & & & & & & & & & & & & & \\
\hline \multirow[t]{6}{*}{ D } & $\mathrm{SP}$ & 1 & $2.18^{\circ}$ & $+\cdots$ & & & & $-{ }^{*}$ & & & & & & & & & & \\
\hline & & 2 & $2.19^{\circ}$ & $+\cdots$ & $+\cdots$ & & & & & & & & & $-{ }^{\cdot}$ & & $-\cdots$ & & \\
\hline & & 3 & 0.95 & + & & & & $-\cdot$ & & & & & & & & & & \\
\hline & MF & 1 & $1.49^{\circ}$ & $+\cdots$ & $+{ }^{*}$ & & & & & & & & & & & & & \\
\hline & & 2 & $1.97^{*}$ & $+\cdots$ & & & & & & & & $-{ }^{*}$ & $-\cdots$ & & & & $+{ }^{*}$ & \\
\hline & & 3 & $2.43^{\cdots}$ & $+\cdots$ & & & & & & & & & & & & & & \\
\hline \multicolumn{19}{|c|}{ Cletocamptus deitersi } \\
\hline \multirow[t]{3}{*}{$\mathrm{C}$} & $\mathrm{SP}$ & 1 & $1.67^{\cdots}$ & $+\cdots$ & $+{ }^{\cdot}$ & & & & & & & & & & & & & \\
\hline & & 2 & 1.36 & $+\cdots$ & & $+^{\circ}$ & & & & & & & & & & & & \\
\hline & & 3 & 1.06 & + & & & & $-{ }^{*}$ & $++^{\circ}$ & & & & & & & & & \\
\hline \multirow[t]{3}{*}{$\mathrm{D}$} & $\mathrm{SP}$ & 1 & 1.22 & $+\cdots$ & & $++^{\cdot}$ & & & & & & & & & & & & \\
\hline & & 2 & $1.47^{\circ}$ & $+\cdots$ & & & $+\cdots$ & & $+\cdots$ & & & $-\cdots$ & & & $-\cdots$ & $-\cdots$ & & $-\cdots$ \\
\hline & & 3 & 0.79 & $+\cdots$ & & & & & & & & & $+{ }^{\cdot}$ & & & & & \\
\hline
\end{tabular}

pronounced and significant positive correlation at the 1 to $2.2 \mathrm{~cm}$ midpoint distance. Among them, most showed highly significant autocorrelation $(p<0.01)$. Correlograms typically showed a similar pattern at loworder (short distance) scales; specifically, a highly significant positive autocorrelation was present at the first or second distance, coupled with a quick drop to nonsignificance at the following distance (examples are shown in Fig. 3i Tables 1, 2). At high-order (longer distance) scales, 2 types of patterns were detected. The first pattern was marked by irregular fluctuation of non-significant or significant points around zero after the first 2 or 3 distances (Fig. 3A, B). The surface density map indicated that this pattern was the result of a distribution with several small patches irregularly located within the array (see example in Fig. 4A, B). The secondary pattern showed a regular and continuous trend from significant positive to negative values (Fig. 3C, D). Replicates which had such pattern displayed 1 or 2 larger patches (Fig. 4C, D). The majority of replicates $(85 \%)$ belonged to the first pattern, and secondary pattern occasionally occurred in all abundant species.

Replicate arrays (within the same collection and site) were variable for all species. The magnitude of variability differed among collections and sites. Occasion- 
Site=MF Date=July 15

Pseudostemelia wellsi
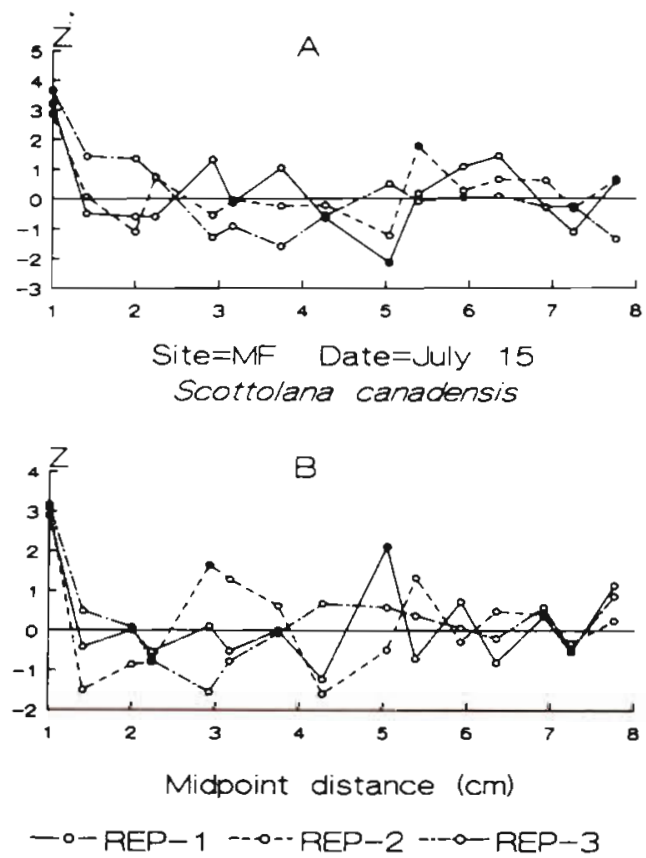

Site $=S P \quad$ Date $=$ July 15

Pseudostennelia wellsi
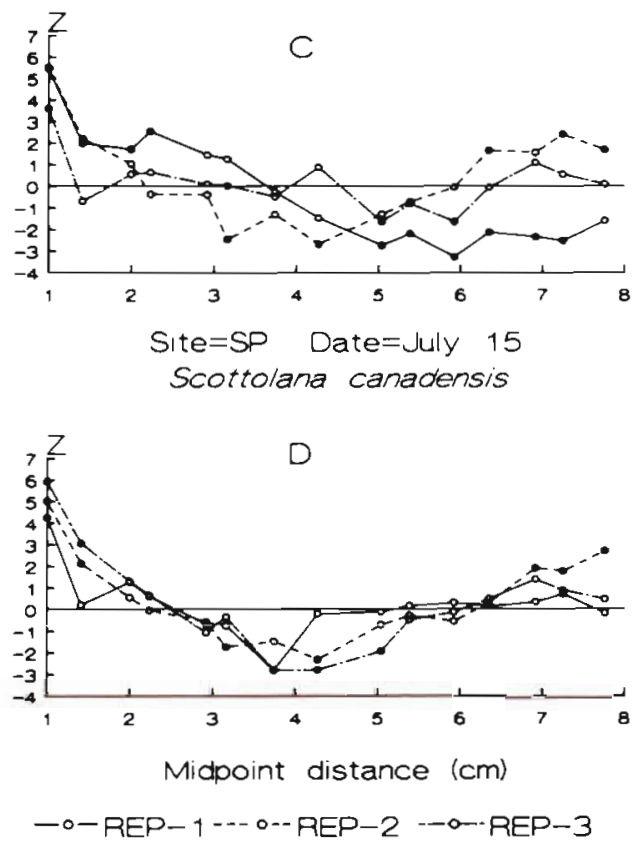

Fig. 3. Examples of spatial correlograms of 3 replicates (here only 2 species, $P$. wellsi and $S$. canadensis, are listed). $(\bullet)$ Significant autocorrelation; (o) non-significant autocorrelation. $\mathrm{Y}$ and $\mathrm{X}$ axes represent standardized autocorrelation value and midpoint distance respectively (see text) ally, similar curves were found for all 3 replicate arrays (Fig. 3D). In most cases, however, the 3 replicates were quite variable, especially where autocorrelation values fluctuated around zero after the first 2 or 3 distances (Fig. 3A, B).

The results of variance-to-mean ratio tests suggest a pattern quite different from the conclusions drawn from correlograms (Tables $1 \& 2$ ). Most replicates of Scottolana canadensis and Nannopus palustris displayed significant values. Significant values were most common when density was high, a problem frequently encountered with dispersion indices (Jumars \& Eckman 1983, Thrush et al. 1989). For example, summer samples of S. canadensis, summer samples of Pseudostenhelia wellsi at SP and spring samples of $N$. palustris at $M F$ showed highly significant values $(p<0.01)$. Low density replicates only showed weak significance or no significance.

An organisms' distribution pattern can be estimated from the correlogram. The patch size corresponds to the distance at which the correlogram first turns zero or negative in value (Sokal 1983). For the most common type of correlogram in this study (Fig. 3A, B), low order positive autocorrelation suggests gradients or patches exceeding the diameter of intersample distance. The significant positive autocorrelation at $1 \mathrm{~cm}$ midpoint distance means that high density of one core corresponds with its adjacent cores. A patch size around 1 to $2 \mathrm{~cm}^{2}$ (or less) could explain this observation. The positive autocorrelation at distance $1.4 \mathrm{~cm}$, which is supported by positive autocorrelation at $1 \mathrm{~cm}$ midpoint distance, indicates an approximate $4 \mathrm{~cm}^{2}$ patch size. The 5 species had basic patch sizes that ranged from 1 to $4 \mathrm{~cm}^{2}$ ( 2 to 4 cores) for most species and replicate combinations.

The inference for high-order distance (the distribution of 'patches' in the sampling array) is dependant on the low-order distance correlation and overall pattern exhibited in the correlogram (Sokal 1979). High order positive autocorrelation suggests a symmetrical surface or a regular arrangement of patches within the array, while high order negative value indicates a larger patch size. Haphazard fluctuations of a significant point around zero (the most common pattern found in this study) only suggest irregularity of small patches and contribute little to identification of larger patches. For the secondary type of correlogram, the high order of significant negative points suggested the boundary of the larger patches. The patch sizes cover the area the diameter of which is the distance at which correlation turn to significant negative values. For example, at $\mathrm{SP}$ in the August sample, the correlogram for Scottolana canadensis showed continuous decrease from significant positive to negative value at the distance 3.2 or $3.7 \mathrm{~cm}$ and suggested 8 to $10 \mathrm{~cm}^{2}$ large patches. The surface density map also supported this (Fig. 4C). In total, only $12(18 \%)$ species and replicate combination of the secondary type showed the larger patch size (6 to $20 \mathrm{~cm}^{2}$ ) (Tables 1 \& 2).

The relationship between density and patch size was species-and site- or even replicate-specific. The scale of patchiness of some species tended to increase in size 
when density increased. At SP in summer, Pseudostenhelia wellsi and Scottolana canadensis were very abundant. The patch size was larger for both species though there was an exception for $P$. wellsi (replicate 3). Significant positive autocorrelation occurred at both 1 and $1.4 \mathrm{~cm}$ midpoint distances or larger, which sug-
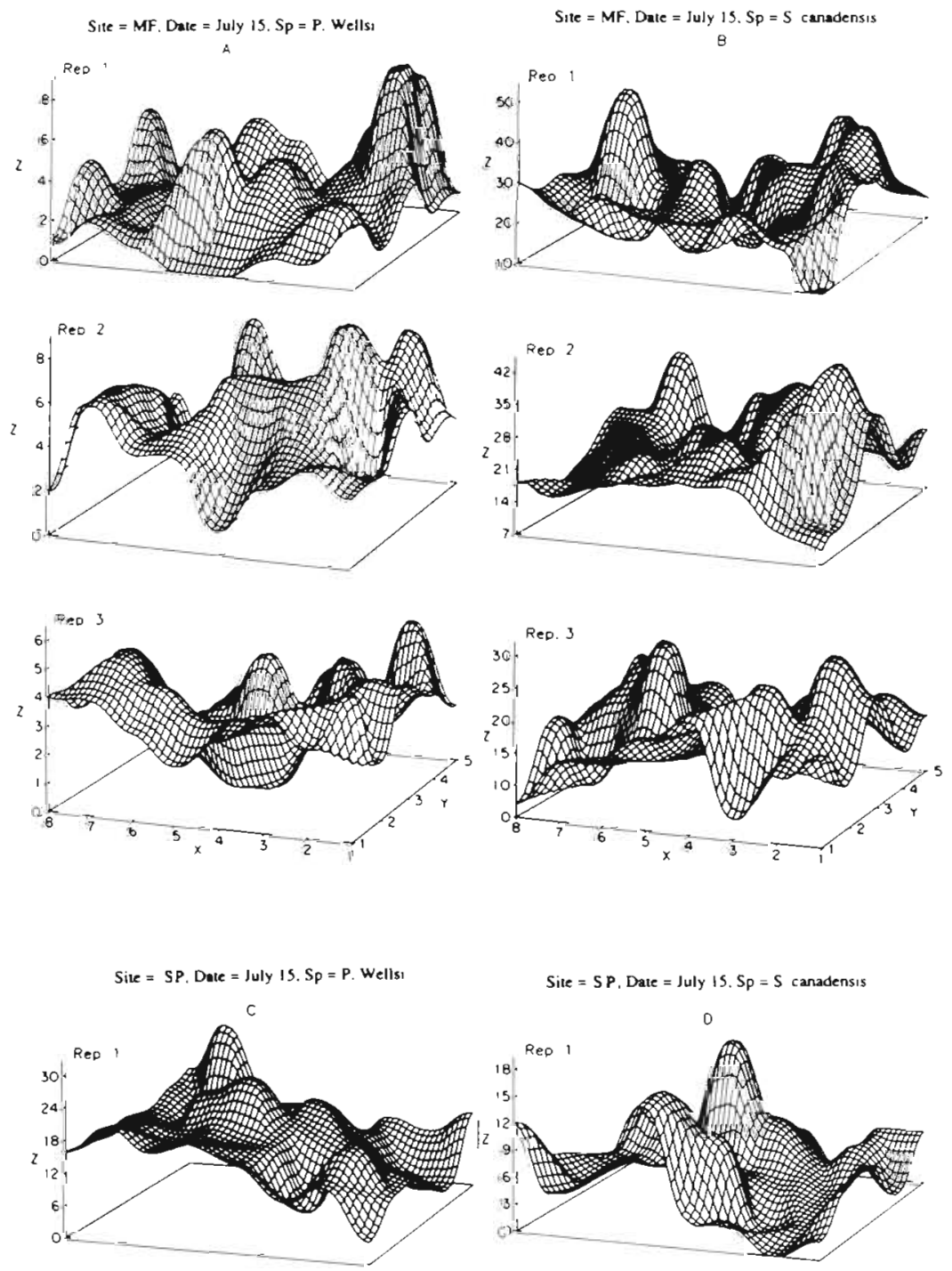

Site $=S P$. Date $=J u l y$ is. $S P=S$ canadens $1 S$
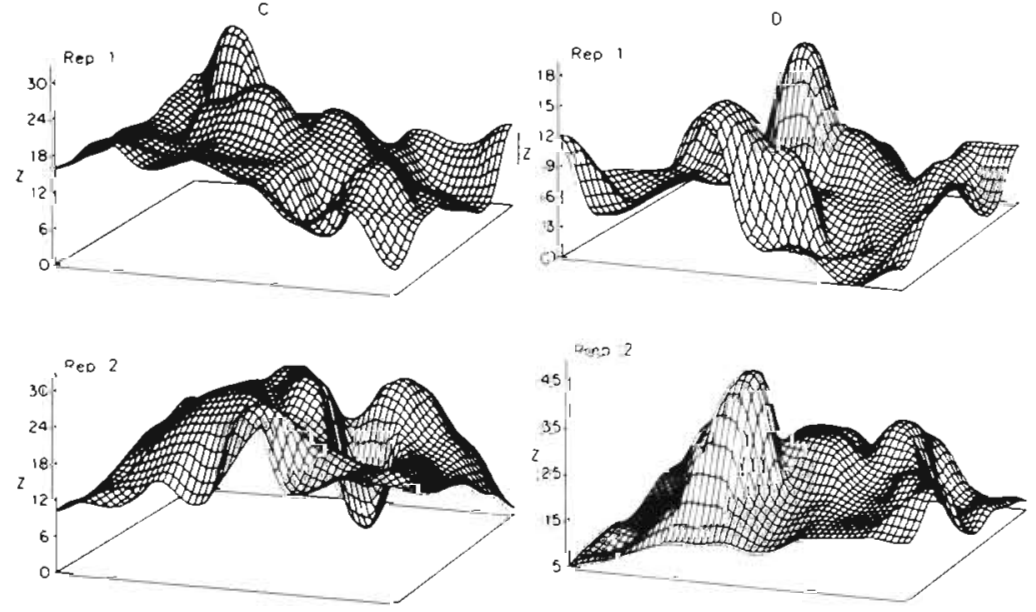

Fig. 4. Examples of spatial density maps of 3 replicates (here only 2 species, Pseudosterhelia wellsi and Scottolana canadensis, are listed)
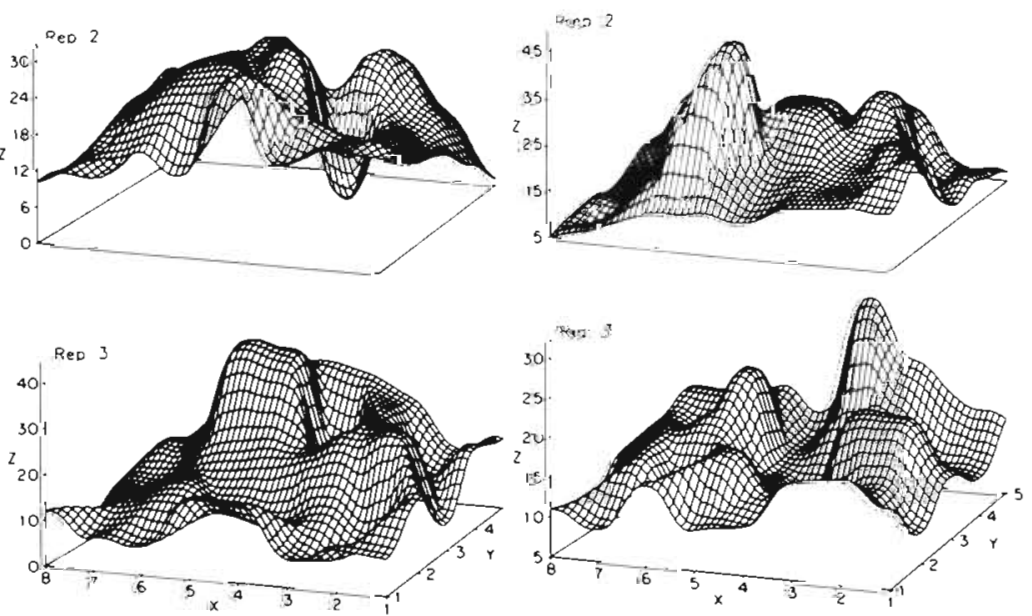
gested that high density corresponded not only to adjacent but also to diagonal cores. The high-order negative autocorrelation indicated larger patches around 8 to $19 \mathrm{~cm}^{2}$ (Figs. 3C, D \& 4C, D). But at the MF site, $S$ canadensis did not increase patch size though extremely high density existed (Figs. 3B \& 4B). The larger patch size and high-order negative autocorrelations were also found in lower density replicates, i.e. 2 replicates of Microarthridion cf. littorale in July at MF. High density of Nannopus palustris in MF samples also failed to yield larger patches.

\section{Scale of variability}

At the SP site, both collections were under moderate flow conditions, one ebbing tide and the other flooding tide. Three-way ANOVA for the spatial variation study indicated that significant variation in density only occurred at the species and sample levels (Table 3). Two-way ANOVA for each species illustrated that the density variations of 4 dominant species $(97 \%$ of total individuals) were different from each other (Table 4). Pseudostenhelia wellsi and Cletocamptus deitersi did not show significant difference at any level. Significant differences were found among samples at the meter scale distances for Scottolana canadensis in both sampling times. Significant interaction between sampling time and transect for Microarthridion cf. littorale suggested that density changed over collecting time.

Calculation of variance components indicated that the subsample scale $(\mathrm{cm})$ explained most of the spatial variation for all 4 species analyzed (Table 5). Of the 3 sampling scales, the density difference between $\mathrm{cm}$ scales contributed from 56.9 to $75.7 \%$ of the variance. The dekameter scale, on the other hand, contributed negligibly to variance $(0$ to $7.1 \%)$. The meter-scalevariance component contributed 9.8 to $18.9 \%$ of total.

\section{DISCUSSION}

Results from our sampling regime suggest that aggregation at small-spatial scales $(\mathrm{cm})$ is a common and striking, yet consistent feature for meiobenthic copepods. Significant heterogeneity of spatial pattern at distances of 1.4 to $2 \mathrm{~cm}$ was found for all abundant species in all seasons and habitats studied. This level of variation was always observed, and even strong diurnal changes associated with tidal stage and water cover did not effect the scale of aggregation at this study site (Fleeger et al. 1990). ANOVA results also support the idea that small-scale aggregation was prevalent, usually overwhelming even meso-scale variation found at the pond site. The high proportion (57 to $76 \%$ ) of variation associated with the subsample (cm scale) level (only 9.8 to $18.9 \%$ associated with the meter scale) suggests that harpacticoid aggregation in the SP site is due mainly to very small-scale features, and that this heterogeneous distribution is found throughout the habitat.

Finding significant heterogeneity at small-spatial scales (cm) for meiofauna is not novel. Findlay (1981) detected aggregation at 3 to $5 \mathrm{~cm}^{2}$ in estuarine mud and sand sediment, Hicks (1979) found 2 to $12 \mathrm{~cm}$ diameter aggregations in a estuarine sandflat, Nixon (1976) measured 2.2 to $5.5 \mathrm{~cm}$ clumps in a high energy beach, Hogue (1982) found aggregations at 2 to $3 \mathrm{~cm}$ distances on the continental shelf and Eckman \& Thistle (1988) detected $2.56 \mathrm{~cm}^{2}$ aggregations in the deep sea. Our study confirms that small-scale variability acts in a similar fashion throughout habitats and for abundant species. Such findings are important in planning studies that seek the cause of small-scale patchiness. Tests may be conducted over a variety of conditions (i.e. at different locations or seasons within a habitat, under different tidal conditions or with different taxa) with the assurance that patterns will be fundamentally similar.

Table 3. Three-way ANOVA results for the effect of tide, species and transect on the density of harpacticoid copepods (data were ln $(x+1)$ transformed $)$

\begin{tabular}{lrrr}
\hline Source of variation & df & Sum of squares & F-value \\
\hline Sampling time (2) & 1 & 0.05 & $0.02 \mathrm{~ns}$ \\
Species (3) & 2 & 56.20 & $23.31 \cdots$ \\
Transect (3) & 2 & 2.78 & $0.44 \mathrm{~ns}$ \\
Time $\times$ Species & 2 & 0.92 & $0.95 \mathrm{~ns}$ \\
Species $\times$ Transect & 4 & 4.82 & $2.49 \mathrm{~ns}$ \\
Transect $\times$ Time & 2 & 4.87 & $5.04 \mathrm{~ns}$ \\
Time $\times$ Species $\times$ Transect & 4 & 1.93 & $1.26 \mathrm{~ns}$ \\
Rep (Time $\times$ Species $\times$ Transect) & 36 & 13.86 & $1.94 \cdots$ \\
Error (Subsample) & 162 & 32.25 & \\
Total & 215 & 117.70 & \\
- Significant, p<0.01; ns: not significant & & & \\
\hline
\end{tabular}


Table 4. F-ratios and levels of significance associated with factors, interaction, sample and subsample in four 2-way ANOVAs

\begin{tabular}{|lccccc|}
\hline Source of variance & df & P. wellsi & S. canadensis & M. cf. littorale & C. deitersi \\
\hline Time & 1,2 & 0.24 & 0.43 & 0.23 & 1.71 \\
Transect (dekameter scale) & 2,2 & 0.64 & 1.61 & 1.03 & 1.61 \\
Time $\times$ Tran. & 2,12 & 1.92 & 2.04 & $5.10^{*}$ & 1.32 \\
Sample (Time $\times$ Tran.) (meter scale) & 12,54 & 1.89 & 2.21 & 1.69 & 1.82 \\
- Significant at 0.05 level & & & & \\
\hline
\end{tabular}

Our results also suggest that future dispersion studies using small numbers of contiguous cores should be extensively replicated. The autocorrelation results revealed large variations in patch size and density among replicates for some collections (see Tables $2 \& 3$, and Fig. 4). Different conclusions concerning patch size could sometimes be drawn depending upon which replicate was observed, and replication is the only way to verify the true scale of aggregation.

Given that small-scale aggregation is a significant feature of the biology of meiofauna, it is relevant to ask questions about patch size variability and about the distribution of patches (Elliott 1977). The size of our basic corer was $0.5 \mathrm{~cm}^{2}$, and the largest sampling array was $45 \mathrm{~cm}^{2}$. Thus, a patch size less than $0.5 \mathrm{~cm}^{2}$ or larger than $45 \mathrm{~cm}^{2}$ could not be detected by our procedures. The position of each individual for each species must be measured (like mapping tree positions) to determine the smallest patch size. Such techniques are called nearest neighbor techniques (Clark \& Evans 1954), but, unfortunately, cannot be applied to meiofauna because their small size and mobility make it impossible to determine the position of individuals. For large-scale patchiness, an increase in sampling unit area would be required. Unfortunately, this leads to a prohibitively large sampling effort. Patch size, however, did show 2 patterns in our study; the more common was smaller (1 to $4 \mathrm{~cm}^{2}$ ), while the rare one was larger $\left(6\right.$ to $20 \mathrm{~cm}^{2}$ ). For each abundant species, patch size was variable from small to large within the smallscale range depending on site, collecting date and even replicate.

Many factors are known to cause heterogeneous small-scale distributions (Fleeger \& Decho 1987). Gen- erally, biotic influences are thought to play a dominant role (Findlay 1981). Interspecific interactions influence distribution (Heip \& Engels 1977. Chandler \& Fleeger 1987), and some harpacticoids actively seek high density patches of diatoms (Decho \& Castenholz 1986 , Decho \& Fleeger 1988). Reproductive activities may cause aggregation as individuals seek mating partners. Small-scale disturbance caused by fish and macrofauna feeding or other activities also affect smallscale patchiness (Thistle 1980). However, microphysical gradients, often influenced by biogenic processes (Thistle et al. 1984, Fleeger \& Gee 1986, Fleeger \& Decho 1987), can be primary effectors depending on local habitat condition (Hogue 1982, Hogue \& Miller 1981, Decho et al. 1985, Hicks 1984).

It is now well-known that harpacticoids disperse either actively or passively in large numbers through the water column at high tide (Palmer 1988). Factors that determine where individuals settle and how they adjust their positions after settlement may prove critical to understanding patchiness (Palmer 1988). The previous studies indicate that either passive (Eckman 1983, DePatra \& Levin 1989) or both passive and active processes (Kern \& Taghon 1986) determine initial settlement. In either one of these processes, micro-habitats (small-scale irregularities of sediment topography, grass shots and feeding pits) may play an very important role in determining spatial distribution pattern. Grass shoots (Eckman 1983), sediment ripple crests (Hogue \& Miller 1981) and macrofauna burrows (Branch \& Pringle 1987, DePatra \& Levin 1989) have been directly or indirectly shown to play a role in smallscale spatial distribution regulation.

No above-ground structure (such as grass shoots)

Table 5. Percentage variance component associated with factors, interaction, sample and subsample for 4 dominant species

\begin{tabular}{|lccrc|}
\hline Source of variance & P. wellsi & S. canadensis & M. cf. littorale & C. deitersi \\
\hline Time & 0.0 & 0.0 & 0.0 & 0.7 \\
Transect (dekameter scale) & 0.0 & 7.1 & 0.5 & 4.5 \\
Time $\times$ Tran. & 10.7 & 12.1 & 32.8 & 3.6 \\
Sample (Time $\times$ Tran.) (meter scale) & 16.5 & 18.9 & 9.8 & 15.5 \\
Subsample (Samp. (Time $\times$ Tran.]) (cm scale) & 72.8 & 61.9 & 56.9 & 75.7 \\
\hline
\end{tabular}


was present at either sampling site; however, there were innumerable small-scale irregularities in the sediment-surface topography (Decho \& Fleeger 1988). These small-scale irregularities may be caused by small fish and shrimp or crab feeding or other activities (Sun pers. obs.). Although macrofauna are rare at this site, another important cause of irregularities may be the fauna itself. Direct evidence of tube-building by Pseudostenhelia wellsi adding cohesiveness to the sediment microstructure which attracts the burrow-dwelling Scottolana canadensis (Chandler \& Fleeger 1987) suggests a role of meiofauna in altering sediment conditions. These small irregularities may either provide food traps for meiofauna under hydrodynamic effects or directly attract meiofauna through their behavioral response. Both processes could contribute significantly to small-scale aggregation. At the DF site, Decho \& Fleeger (1988) found Microarthridion cf. littorale are positively correlated with high concentrations of diatoms and the patches of diatom were very similar to the patches of the species. If interactions between the sediment microhabitats, hydrodynamic and animal behavior occur, it is not difficult to explain the consistency of small-scale aggregation and its size variation.

Service \& Bell (1987) found that harpacticoids tend to disperse under high density conditions, suggesting that density may be a significant factor in regulating patch size. Analysis of our data reveals no predictable relationship between patch size and population density for the abundant harpacticoids however. The patch size of a given species was either large or small under either high or low density conditions, and variability occurred among replicate sampling units. Density at this sampling site changes with tidal cycle, yet patch size was not related to tidal stage (Fleeger et al. 1990). Previous studies also yield inconsistent results. Findlay (1981) found that some meiofauna (gastrotrichs and one species of copepod) were less aggregated when density was high. On the other hand, both Nixon (1976) and Hicks (1984) showed that species tend to be more aggregated when density is high. It is likely that factors that determine patch size act under both high and low density conditions to contribute to patchiness.

The consistency of small-scale aggregation does not mean patches are static. On the contrary, small-scale aggregation and its effectors (for example, sediment microhabitat) may be very dynamic. Although the size of patch remained constant at the small scale $(\mathrm{cm})$, patches may change in size, position, magnitude and shape. Life expectancy of a patch is very difficult to measure, and no direct evidence is available on patch longevity. However, the variations of 3 replicates in terms of their sizes, positions, magnitudes and shapes of patches indirectly support the theory that patches are dynamic with spatio-temporal changes.
Small-scale variability is a real, detectable property of meiofauna. It has been identified in virtually every study ever conducted. This study represents the most extensive effort ever conducted to catalog patchiness. Our findings suggest that small-scale variability is a consistent feature for abundant species, and that smallscale variability contributes most to the overall sampling variability of a habitat. Thus, small-scale distribution studies can take place under a variety of environmental conditions with a true representation of pattern. Nevertheless the details of spatial pattern can vary. Patches are most frequently at very small scales (less that $5 \mathrm{~cm}^{2}$ ) but will sometimes be variable in size (larger). More troubling is the observation that variation in spatial pattern among replicates is quite high. This variation makes conclusions about the intensity of patchiness without replication tenuous and suggests that multiple collections should be made. Progress in understanding the cause of variation of patchiness will be made when the regulation of patchiness is understood. Fertile areas of study might be to investigate factors that operate at very small-spatial scales; behavior and micro-habitat are likely candidates. The causes of distribution patterns will best be determined by more closely coupling micro-habitat, behavior, hydrodynamic, and microbial studies, and by the use of manipulative experiments in both field and laboratory settings.

Acknowledgements. We thank T. Nguyen, S. Mills for sorting samples, Dr B. Moser for the valuable statistic advice and autocorrelation program, and Dr K. Carman, Dr B. Moser and J. McCall for improving earlier drafts of this manuscript. We also thank the Louisiana Universities Marine Consortium (LUMCON) for the use of boats and laboratory facilities. This work was supported by Sigma Xi Grants- In-Aid of Research to Bin Sun.

\section{LITERATURE CITED}

Branch, G. M., Pringle, A. (1987). The impact of the sand prawn Callianassa kraussi Stebbing on sediment turnover and on bacteria, meiofauna, and benthic microflora. J. exp mar. Biol. Ecol. 107: 219-235

Chandler, G. T., Fleeger, J. W. (1983). Meiofaunal colonization of azoic estuarine sediment in Louisiana: mechanisms of dispersal. J. exp. mar. Biol Ecol. 69: 175-188

Chandler, G. T., Fleeger, J. W. (1987). Facilitative and inhibitory interactions among estuarine meiobenthic harpacticoid copepods. Ecology 68: 1906-1919

Clark, P. J., Evans, F. C. (1954). Distance to nearest neighbour as a measure of spatial relationships in populations. Ecology $35: 445-453$

Cliff, A. D., Haggett, P., Ord, J. K., Bassett, K. A., Davies, R. B. (1975). Elements of spatial structure. Cambridge University Press, Cambridge, p. 145-224

Decho, A. W., Castenholz, R. W. (1986). Spatial patterns and feeding of meiobenthic harpacticoid copepods in relation to resident microbial flora. Hydrobiologia 131: 87-96 
Decho, A. W., Fleeger, J. W. (1988). Microscale dispersion of meiobenthic copepods in response to food-resource patchiness. J. exp. mar. Biol. Ecol 118: 229-244

Decho, A. W., Hummon W. D., Fleeger, J. W. (1985). Meiofauna-sediment interactions around subtropical seagrass sediments using factor analysis. J. mar Res. 43: $237-255$

DePatra, K. D., Levin, L. A. (1989). Evidence of the passive deposition of meiofauna into fiddler crab burrows. J. exp. mar. Biol. Ecol. 125: 173-192

Eckman, J. E. (1983). Hydrodynamic processes affecting benthic recruitment. Limnol. Oceanogr. 28: 241-257

Eckman, J. E., Thistle, D. (1988). Small-scale spatial pattern in meiobenthos in the San Diego Trough. Deep Sea Res. 35: $1565-1578$

Elliott, J. M. (1977). Some methods for the statistical analysis of samples of benthic invertebrates. Freshwater Biological Association. 1-160 pp.

Findlay, S. E. G. (1981). Small-scale spatial distribution of meiofauna on a mud- and sandflat. Estuar. coast. Shelf Sci. 12: $471-484$

Findlay, S. E. G. (1982). Influence of sampling scale on apparent distribution of meiofauna on a sandflat. Estuaries 5: $322-324$

Fleeger, J. W., Chandler, G. T. (1983). Meiofauna responses to an experimental oil spill in a Louisiana saltmarsh. Mar Ecol. Prog. Ser. 11: 257-264

Fleeger, J. W., Decho, A. W. (1987). Spatial variability of interstitial meiofauna: a review. Stygologia 3: 35-54

Fleeger, J. W., Gee, J. M. (1986). Does interference competition determine the vertical distribution of meiobenthic copepods?. J. exp. mar. Biol. Ecol. 95: 173-181

Fleeger, J. W., Palmer, M. A., Moser, E. B. (1990), On the scale of aggregation of meiobenthic copepods on a tidal mudflat. P.S.Z.N.I.: Mar. Ecol. 11. 227-237

Fleeger, J. W., Thistle, D., Thiel, H. (1988). Sampling equipment. In: Higgins, R. P., Thiel, H. (eds.) Introduction to the study of meiofauna. Smithsonian Institution Press., Washington, D.C., p. 115-125

Heip, C., Engels, P. (1977). Spatial segregation in copepod species from a brackish water habitat. J. exp. mar. Biol. Ecol. 26: 77-96

Hicks, G. R. F. (1979). Pattern and strategy in the reproductive cycles of benthic harpacticoid copepods. In: Naylor, E., Hartnoll, R. G. (eds.) Cyclic phenomena in marine plants and animals. Pergamon Press, Oxford and New York, p. 139-147

Hicks, G. R. F. (1984). Spatio-temporal dynamics of a meiobenthic copepod and the impact of predation-disturbance. J. exp. mar. Biol. Ecol. 81: 47-72

Hogue, E. W (1982). Sediment disturbance and the spatial distributions of shallow water meiobenthic nematodes on the open Oregon coast. J. mar Res. 40: 551-573

Hogue, E. W., Miller, C. B. (1981). Effects of sediment microtopography on small-scale spatial distributions of meiobenthic nematodes. J. exp. mar. Biol. Ecol. 53: 181-191

Jumars, P. A., Eckman, J. E. (1983) Spatial structure within deep-sea benthic communities. In: Rowe, G. T. (ed.) The sea, Vol. 8. John Wiley, New York, p. 399-451

This article was presented by $S$. Meyers, Baton Rouge, Louisiana, USA
Kern, J. C., Bell, S. S. (1984). Spatial heterogeneity in sizestructure of meiofaunal-sized invertebrates on small-spatial scales (meters) and its implications. J. exp. mar. Biol. Ecol. 78: 221-235

Kern, J. C., Taghon, G. L. (1986). Can passive recruitment explain harpacticoid copepod distributions in relation to epibenthic structure?. J. exp. mar. Biol. Ecol. 101: 1-23

Nixon, D. E. (1976). Dynamics of spatial pattern for the gastrotrich Tetranchyroderma bunti in the surface sand of high energy beaches. Int. Rev. ges. Hydrobiol. 61: 211-248

Palmer, M. A. (1986). Hydrodynamics and structure: interactive effects on meiofauna dispersal. J. exp. mar Biol. Ecol. 104: $53-68$

Palmer, M. A. (1988). Dispersal of marine meiofauna: a review and conceptual model explaining passive transport and active emergence with implications for recruitment. Mar. Ecol. Prog. Ser. 48: 81-91

Palmer, M. A., Brandt, R. R. (1981). Tidal variation in sediment densities of marine benthic copepods. Mar. Ecol. Prog. Ser. 4: $207-212$

Phillips, F. E., Fleeger, J. W. (1985). Meiofauna meso-scale variability in two estuarine habitats. Estuar. coast. Shelf Sci. 21: $754-756$

Service, S. K., Bell, S. S. (1987). Density-influenced active dispersal of harpacticoid copepods. J. exp. mar. Biol. Ecol. 114: 49-62

Sokal, R. R. (1979). Ecological parameters inferred from spatial correlograms. In: Patil, G. P., Rosenzweig, M. (eds.) Contemporary quantitative ecology and related ecometrics. International Co-operative Publishing House, Fairland, p. $167-196$

Sokal, R. R. (1983). Analyzing character variation in geographic space. In: Felsenstein, J. (ed.) Numerical taxonomy. Springer-Verlag, Berlin, Heidelberg, p.: 384-403

Sokal, R. R., Oden, N. L. (1978). Spatial autocorrelation in biology 2 . Some biological implications and four applications of evolutionary and ecological interest. Biol. J. Linn. Soc. 10: 229-249

Sokal, R. R., Thomson, J. D. (1987). Applications of spatial autocorrelation in ecology. In: Legendre, P., Legendre, L. (eds.) Developments in numerical ecology. Springer-Verlag, Berlin, p. 431-466

Thistle, D. (1978). Harpacticoid dispersion patterns: implications for deep-sea diversity maintenance. J. mar. Res. 36: $377-397$

Thistle, D. (1980). The response of a harpacticoid copepod community to a small-scale natural disturbance. J. mar. Res. 38: 381-395

Thistle, D., Eckman, J. E. (1988). Response of harpacticoid copepods to habitat structure at a deep-sea site. Hydrobiologia 167/168: 143-149

Thistle, D., Reidenauer, A., Findlay, R. H., Waldo, R. (1984). An experimental investigation of enhanced harpacticoid (Copepoda) abundances around isolated seagrass shoots. Oecologia 63: 295-299

Thrush, S. E., Hewitt, J. E., Pridmore, R. D. (1989). Patterns in the spatial arrangements of polychaetes and bivalves in intertidal sandflats. Mar. Biol. 102: 529-535

Manuscript first received: October 4, 1990

Revised version accepted: January 15, 1991 